Journal of

Molecular Microbiology

and Biotechnology
J Mol Microbiol Biotechnol 2016;26:269-276

DOI: $10.1159 / 000445687$
Received: January 22, 2016

Accepted: March 20, 2016

Published online: May 14, 2016

\title{
Development of Chemically Defined Media to Express Trp-Analog-Labeled Proteins in a Lactococcus lactis Trp Auxotroph
}

\author{
Jinfeng Shao ${ }^{\mathrm{a}}$ Marcelo F.M. Marcondes ${ }^{\mathrm{b}} \quad$ Vitor Oliveira $^{\mathrm{b}} \quad$ Jaap Broos $^{\mathrm{a}}$ \\ a Laboratory of Biophysical Chemistry and Groningen Biomolecular Sciences and Biotechnology Institute (GBB),

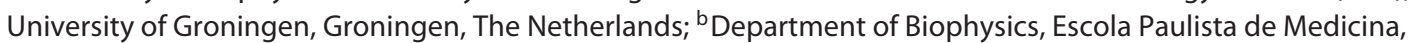 \\ Universidade Federal de São Paulo, São Paulo, Brazil
}

\section{Key Words}

Alloprotein · Lactococcus lactis · Synthetic medium ·

Tryptophan analog

\begin{abstract}
Chemically defined media for growth of Lactococcus lactis strains contain about 50 components, making them laborious and expensive growth media. However, they are crucial for metabolism studies as well as for expression of heterologous proteins labeled with unnatural amino acids. In particular, the L. lactis Trp auxotroph PA1002, overexpressing the tryptophanyl tRNA synthetase enzyme of L. lactis, is very suitable for the biosynthetic incorporation of Trp analogs in proteins because of its most relaxed substrate specificity reported towards Trp analogs. Here we present two much simpler defined media for L. lactis, which consist of only 24 or 31 components, respectively, and with which the L. lactis Trp auxotroph shows similar growth characteristics as with a 50-component chemically defined medium. Importantly, the expression levels of two recombinant proteins used for evaluation were up to 2-3 times higher in these new media than in the 50-component medium, without affecting the Trp analog incorporation efficiency. Taken together, the simplest chemically defined media reported so far for L. lactis are presented. Since L. lactis also shows
\end{abstract}

\section{KARGER}

E-Mail karger@karger.com www.karger.com $/ \mathrm{mmb}$

\section{(9) 2016 The Author(s) \\ Published by S. Karger AG, Basel $1464-1801 / 16 / 0264-0269 \$ 39.50 / 0$}

This article is licensed under the Creative Commons AttributionNonCommercial-NoDerivatives 4.0 International License (CC BYNC-ND) (http://www.karger.com/Services/OpenAccessLicense) Usage and distribution for commercial purposes as well as any distribution of modified material requires written permission. auxotrophy for Arg, His, lle, Leu Val, and Met, our simplified media may also be useful for the biosynthetic incorporation of analogs of these five amino acids.

(c) 2016 The Author(s)

Published by S. Karger AG, Basel

\section{Introduction}

For the residue-specific labeling of a recombinant protein with a pseudoisosteric unnatural amino acid, an auxotrophic expression host is needed, which, during protein expression, is cultured in a synthetic medium supplemented with the unnatural amino acid and lacking the natural amino acid homolog. Most pseudoisosteric unnatural amino acids have so far been introduced using Escherichia coli as the expression host and grown in the synthetic 15-component M9 medium [Broos, 2014; Budisa, 2004; Connor and Tirrell, 2007; Ross et al., 1997, 2000; Twine and Szabo, 2003]. However, recently we reported the use of Lactococcus lactis as an expression host for the incorporation of Trp analogs in recombinant proteins. The Gram-positive L. lactis is known as an attractive expression host for proteins, including membrane proteins [Kunji et al., 2003]. It can grow under aerobic or anaerobic conditions and it has a relatively low proteolytic activity. Tightly controlled gene expression systems are avail- 
able [Kuipers et al., 1997; Morello et al., 2008]. Moreover, L. lactis is auxotrophic towards Arg, His, Ile, Leu Val, and Met [Zhang et al., 2009]. For the incorporation of Trp analogs, a L. lactis Trp auxotroph strain, PA1002, was developed [El Khattabi et al., 2008]. Compared to E. coli, the translation machinery of PA1002 was found more relaxed towards Trp analogs. The variety of Trp analogs translated by PA1002 could be significantly enhanced via the plasmid-based coexpression of the tryptophanyl tRNA synthetase enzyme (lacTrpRS) of L. lactis [Petrovic et al., 2013b; Shao et al., 2015]. This made it possible to biosynthetically incorporate Trp analogs with bulky substituents in recombinant proteins, which had not been biosynthetically incorporated before. Thus, methylated, brominated, chlorinated, and difluoro-substituted Trp analogs can now be introduced with high efficiency while maintaining a high alloprotein yield. Using this expression system, we recently also reported the incorporation of $\beta$-(1azulenyl)-L-alanine, which is an amino acid featuring special spectroscopic and electronic properties, including an intense blue color [Shao et al., 2015]. Currently, PA1002, coexpressing lacTrpRS, is the most versatile expression system known for the incorporation of Trp analogs. For Trp analog-labeled protein production, a chemically defined medium (CDM) is needed to ascertain that no Trp is available during protein expression, while keeping the cells viable for $16 \mathrm{~h}$. The synthetic media used for L. lactis are much more complex than those for E. coli [Aller et al., 2014; Jensen and Hammer, 1993; Otto et al., 1983; Poolman and Konings, 1988; Zhang et al., 2009]. They contain about 50 components, making them relatively labor intensive and costly compared to the synthetic M9 medium used for E. coli. In this work we explored the possibility to simplify a 50-component CDM for $L$. lactis while maintaining the growth characteristics, alloprotein expressions levels, and Trp analog incorporation efficiency. This goal could be reached by leaving out more than half of the components of the CDM used so far for PA1002. Interestingly, an alloprotein expression yield of up to 2-3 times higher than with the 50-component CDM was obtained using the newly developed media, as exemplified for two model proteins.

\section{Results}

Evaluation of Less Important Components in a 50-Component CDM

Previous L. lactis Trp auxotroph PA1002 expression experiments were conducted with a CDM consisting of
50 components and using phosphate salts for $\mathrm{pH}$ buffering [Poolman and Konings, 1988] (table 1). In the present work we refer to this medium as CDMbasis. To simplify this medium, knowledge is needed about the importance of each component for cell growth. Such information has recently been provided by Zhang et al. [2009], who developed two new synthetic media for L. lactis consisting of 57 components. All CDMbasis ingredients, except one, are also present in the media developed by Zhang et al. [2009]. Proper buffering of L. lactis growth media is important as lactic acid is produced during growth, resulting in lowering the $\mathrm{pH}<4.5$, a $\mathrm{pH}$ regime where the cells do not grow. MOPS has been found as an excellent buffering component for L. lactis media [Aller et al., 2014; Jensen and Hammer, 1993] and was included in the new minimal chemically defined media developed in this work. The concentrations of the canonical amino acids are the same or very similar in CDMbasis and the media developed by Zhang et al. [2009], except for glutamic acid, of which the concentration is 7-8 times higher in CDMbasis (table 1).

In the new minimal chemically defined media, all amino acid concentrations are the same as the concentrations reported by Zhang et al. [2009]. They labeled 26 of the non-amino acid components as 'somewhat important' and 'least important' for growth. These compounds were left out in formulating a new minimal (m) CDM. The above changes resulted in a new medium, mCDM20, consisting of 31 components, including the 20 canonical amino acids (table 1). To test this medium, cells were grown in $\mathrm{GM} 17$ at $30^{\circ} \mathrm{C}$ until the exponential phase, were harvested, washed 3 times with PBS, and resuspended in either CDMbasis or mCDM20. The yields of the biomass, expressed as $\mathrm{OD}_{600}$, of L. lactis PA1002 after $16 \mathrm{~h}$ at $30^{\circ} \mathrm{C}$ are presented in figure 1. With CDMbasis, an $\mathrm{OD}_{600}$ of 3.0 was measured while for $\mathrm{mCDM} 20$ the $\mathrm{OD}_{600}$ became 2.8 . It can be concluded that leaving out most of the non-amino acid components in CDMbasis does not affect $L$. lactis PA1002 cell growth under the tested conditions.

\section{Importance of Individual Amino Acids in $m C D M$ for the Growth of PA1002}

For a further simplification of mCDM20, the importance of each of the 20 amino acids for growth was investigated. As the medium is developed for a Trp auxotrophic strain, in all subsequent experiments, Trp was included. Six amino acids are essential for L. lactis growth, namely Met, Ile, Leu, Val, Arg, and His [Zhang et al., 2009]. Using the leave-one-out approach, and thus leaving the other 19 amino acids in the medium, the ef- 
Table 1. Composition of CDMbasis, mCDM20, mCDM7, mCDM11, and mCDM13

\begin{tabular}{|c|c|c|c|c|c|}
\hline Constituents & CDMbasis, g/l & mCDM20, g/l & mCDM7, g/l & mCDM11, g/l & $\mathrm{mCDM} 13, \mathrm{~g} / \mathrm{l}$ \\
\hline $\mathrm{KH}_{2} \mathrm{PO}_{4}$ & 2.5 & 2.6 & 2.6 & 2.6 & 2.6 \\
\hline $\mathrm{K}_{2} \mathrm{HPO}_{4} \times 3 \mathrm{H}_{2} \mathrm{O}$ & 3 & 5.6 & 5.6 & 5.6 & 5.6 \\
\hline Ammonium citrate & 0.6 & & & & \\
\hline Sodium acetate & 1 & & & & \\
\hline Potassium acetate & & 0.76 & 0.76 & 0.76 & 0.76 \\
\hline MOPS & & 12.7 & 12.7 & 12.7 & 12.7 \\
\hline L-Tyrosine & 0.29 & 0.33 & & & 0.33 \\
\hline L-Glutamic acid & 5 & 0.65 & & 0.65 & 0.65 \\
\hline L-Aspartic acid & 0.455 & 0.455 & & & \\
\hline L-Alanine & 0.2375 & 0.2375 & & & \\
\hline L-Glutamine & 0.39 & 0.39 & & 0.39 & 0.39 \\
\hline L-Asparagine & 0.35 & 0.35 & & & 0.35 \\
\hline L-Arginine & 0.125 & 0.72 & 0.72 & 0.72 & 0.72 \\
\hline L-Lysine & 0.4375 & 0.4375 & & & \\
\hline L-Isoleucine & 0.215 & 0.24 & 0.24 & 0.24 & 0.24 \\
\hline L-Methionine & 0.125 & 0.06 & 0.06 & 0.06 & 0.06 \\
\hline L-Phenylalanine & 0.275 & 0.275 & & & \\
\hline L-Serine & 0.3375 & 0.3375 & & 0.338 & 0.338 \\
\hline L-Threonine & 0.225 & 0.225 & & & \\
\hline L-Valine & 0.325 & 0.7 & 0.7 & 0.7 & 0.7 \\
\hline L-Glycine & 0.175 & 0.175 & & 0.175 & 0.175 \\
\hline L-Histidine & 0.15 & 0.17 & 0.17 & 0.17 & 0.17 \\
\hline L-Leucine & 0.475 & 1 & 1 & 1 & 1 \\
\hline L-Proline & 0.675 & 0.675 & & & \\
\hline L-Cysteine & 0.25 & 0.25 & & & \\
\hline Pyridoxal chloride & 0.002 & & & & \\
\hline Vitamin $B_{3}$ & 0.001 & 0.0009 & 0.0009 & 0.0009 & 0.0009 \\
\hline Vitamin $B_{1}$ & 0.001 & & & & \\
\hline Vitamin $\mathrm{B}_{2}$ & 0.001 & 0.0009 & 0.0009 & 0.0009 & 0.0009 \\
\hline Vitamin $\mathrm{B}_{5}$ & 0.001 & 0.0012 & 0.0012 & 0.0012 & 0.0012 \\
\hline $\mathrm{Na}$ - $p$-aminobenzoate & 0.01 & & & & \\
\hline Vitamin $\mathrm{H}$ & 0.01 & & & & \\
\hline Folic acid & 0.001 & & & & \\
\hline Vitamin $B_{12}$ & 0.001 & & & & \\
\hline Orotic acid & 0.005 & & & & \\
\hline Thymidine & 0.005 & & & & \\
\hline Inosine & 0.005 & & & & \\
\hline DL-6,8-Thioctic acid & 0.0025 & & & & \\
\hline Pyridoxamine dichloride & 0.005 & & & & \\
\hline Pyridoxal $\mathrm{HCl}$ & & 0.0048 & 0.0048 & 0.0048 & 0.0048 \\
\hline $\mathrm{MgCl}_{2} \times 6 \mathrm{H}_{2} \mathrm{O}$ & 0.2 & & & & \\
\hline $\mathrm{CaCl}_{2} \times 2 \mathrm{H}_{2} \mathrm{O}$ & 0.05 & & & & \\
\hline $\mathrm{FeCl}_{2} \times 4 \mathrm{H}_{2} \mathrm{O}$ & 0.005 & & & & \\
\hline $\mathrm{ZnSO}_{4} \times 7 \mathrm{H}_{2} \mathrm{O}$ & 0.005 & 0.005 & 0.005 & 0.005 & 0.005 \\
\hline $\mathrm{CoCl}_{2} \times 6 \mathrm{H}_{2} \mathrm{O}$ & 0.003 & & & & \\
\hline $\mathrm{CuSO}_{4} \times 5 \mathrm{H}_{2} \mathrm{O}$ & 0.0002 & & & & \\
\hline $\mathrm{MnSO}_{4} \times \mathrm{H}_{2} \mathrm{O}$ & 0.05 & & & & \\
\hline $\mathrm{MgSO}_{4}$ & & 0.53 & 0.53 & 0.53 & 0.53 \\
\hline Adenine & 0.01 & & & & \\
\hline Uracil & 0.01 & & & & \\
\hline Xanthine & 0.01 & & & & \\
\hline Guanine & 0.01 & & & & \\
\hline Glucose & 20 & 15 & 15 & 15 & 15 \\
\hline Tryptophan & 0.204 & 0.204 & 0.204 & 0.204 & 0.204 \\
\hline
\end{tabular}


Table 2. The $\mathrm{OD}_{600}$ of L. lactis PA1002 after $16 \mathrm{~h}$ at $30^{\circ} \mathrm{C}$ in $\mathrm{mCDM} 7$ complemented with amino acids as indicated

\begin{tabular}{|c|c|c|c|c|c|c|c|c|c|c|c|c|c|c|}
\hline Treatment & \multicolumn{8}{|c|}{ 'S' amino acids } & \multicolumn{5}{|c|}{ 'L' amino acids } & $\mathrm{OD}_{600}$ \\
\hline $\mathrm{A} 2$ & 1 & 1 & 1 & 1 & 1 & 1 & 1 & 1 & 1 & 1 & 1 & 1 & 1 & 2.7 \\
\hline A3 & 1 & 1 & 1 & 1 & 1 & 1 & 1 & 1 & 0 & 0 & 0 & 0 & 0 & 0.6 \\
\hline A4 & 0 & 0 & 0 & 0 & 0 & 0 & 0 & 0 & 1 & 1 & 1 & 1 & 1 & 1.6 \\
\hline A7 & 0 & 0 & 1 & 0 & 0 & 0 & 0 & 0 & 1 & 1 & 1 & 1 & 1 & 2.0 \\
\hline A 8 & 0 & 0 & 0 & 1 & 0 & 0 & 0 & 0 & 1 & 1 & 1 & 1 & 1 & 1.7 \\
\hline A9 & 0 & 0 & 0 & 0 & 1 & 0 & 0 & 0 & 1 & 1 & 1 & 1 & 1 & 1.4 \\
\hline A10 & 0 & 0 & 0 & 0 & 0 & 1 & 0 & 0 & 1 & 1 & 1 & 1 & 1 & 2.2 \\
\hline A11 & 0 & 0 & 0 & 0 & 0 & 0 & 1 & 0 & 1 & 1 & 1 & 1 & 1 & 1.3 \\
\hline A12 & 0 & 0 & 0 & 0 & 0 & 0 & 0 & 1 & 1 & 1 & 1 & 1 & 1 & 1.7 \\
\hline A16 & 0 & 0 & 0 & 0 & 0 & 0 & 0 & 0 & 0 & 0 & 0 & 1 & 0 & 1.8 \\
\hline A 17 & 0 & 0 & 0 & 0 & 0 & 0 & 0 & 0 & 0 & 0 & 0 & 0 & 1 & 1.3 \\
\hline
\end{tabular}

'0' signifies it is not added to mCDM7, whereas ' 1 ' signifies it is added to mCDM7.

Fig. 1. $\mathrm{OD}_{600}$ after $\mathrm{o} / \mathrm{n}$ incubation of PA1002 cultures in CDMbasis, mCDM20, and mCDM20 cultures subjected to the leave-one-out approach for the 20 canonical amino acids.

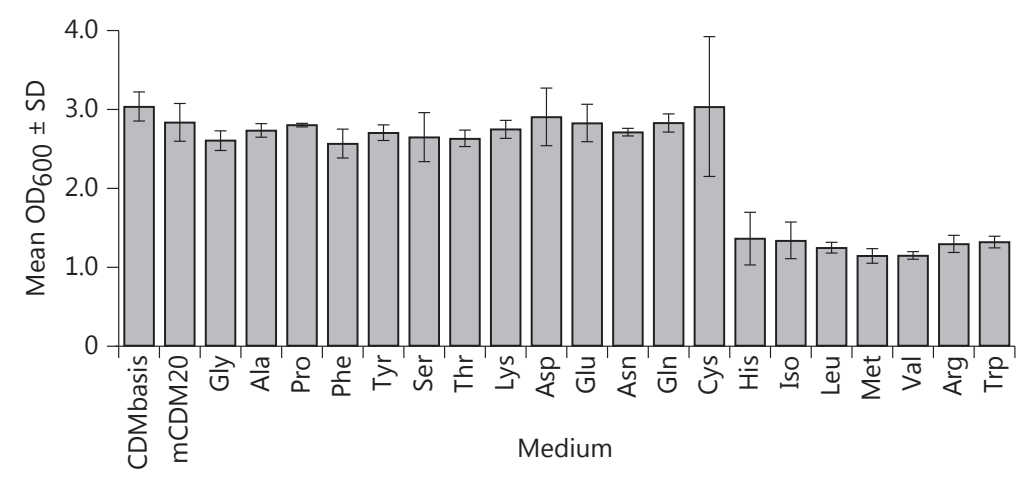

fect on growth of each amino acid was investigated. The $\mathrm{OD}_{600}$ of the 20 cultures after $\mathrm{o} / \mathrm{n}$ growth are presented in figure. 1. These data show that media without Met, Ile, Leu, Val, Arg, or His result in significantly lower $\mathrm{OD}_{600}$ values $(<1.5)$ than obtained for MCDM20 (2.8). Therefore, for good growth of the Trp auxotroph strain PA1002, these 6 amino acids, like Trp, need to be present in the medium. Here, this medium is called mCDM7 (table 1).

Leaving 1 of the other 13 amino acids out from mCDM20 had no or only a minor effect on the $\mathrm{OD}_{600}$ (fig. 1), suggesting that these amino acids are not important for growth. However, with mCDM7 only an $\mathrm{OD}_{600}$ of 1.0 was obtained after $\mathrm{o} / \mathrm{n}$ growth (table 2 , entry A1), significantly less than with mCDM20 (table 2, entry A2). The discrepancy between these experiments can be explained by interaction phenomena taking place between the amino acids. To investigate this, the 13 amino acids were divided in two groups [Zhang et al., 2009]: 'somewhat important (S)' and 'less important (L)' amino acids. 
Table 3. The $\mathrm{OD}_{600}$ of L. lactis PA1002 after $16 \mathrm{~h}$ at $30^{\circ} \mathrm{C}$ in $\mathrm{mCDM} 11$ complemented with amino acids as indicated

\begin{tabular}{llllllll}
\hline Treatment & Pro & Asn & Thr & Ala & Lys & Tyr & OD $_{600}$ after 16 h incubation \\
\hline B1 & 0 & 0 & 0 & 0 & 0 & 0 & 2.4 \\
B2 & 1 & 0 & 0 & 0 & 0 & 0 & 2.3 \\
B3 & 0 & 1 & 0 & 0 & 0 & 0 & 2.7 \\
B4 & 0 & 0 & 1 & 0 & 0 & 0 & 2.3 \\
B5 & 0 & 0 & 0 & 1 & 0 & 0 & 2.4 \\
B6 & 0 & 0 & 0 & 0 & 1 & 0 & 2.1 \\
B7 & 0 & 0 & 0 & 0 & 0 & 1 & 2.6 \\
B8 & 0 & 1 & 0 & 0 & 0 & 1 & 3.2 \\
\hline
\end{tabular}

' 0 ' signifies it is not added to mCDM11, whereas ' 1 ' signifies it is added to mCDM11.

Adding all 8 ' $\mathrm{S}$ ' amino acids to $\mathrm{mCDM} 7$ resulted in an unfavorable growth medium for PA1002 as the $\mathrm{OD}_{600}$ after $\mathrm{o} / \mathrm{n}$ incubation was only 0.6 (table 2 , entry A3). Including all 5 ' $\mathrm{L}$ ' amino acids in mCDM7 enhanced the growth, as the $\mathrm{OD}_{600}$ became 1.6 (table 2, entry A4), a cell density significantly higher as found for $\mathrm{mCDM} 7\left(\mathrm{OD}_{600}=1.0\right)$, but lower when mCDM20 was used. This medium, mCDM7 plus all 5 ' $L$ ' amino acids was used to investigate the impact of each ' $S$ ' amino acid on growth (table 2, entries A5-A12). Including Ser or Gly in this medium resulted in a much higher $\mathrm{OD}_{600}$ of 2.0 and 2.2 , respectively, while including one of the other 6 ' $\mathrm{S}$ ' amino acids minimally affected the growth (table 2). Of the 5 ' $\mathrm{L}$ ' amino acids, only Glu and Gln turned out to be important for growth as the $\mathrm{OD}_{600}$ increased from 1.0 for $\mathrm{mCDM} 7$ to 1.8-1.9 when one of these amino acids was included in mCDM7 (table 2, entries A13-A17). Based on the outcomes of the above first screens of 'S' and ' $L$ ' amino acids, a new mCDM medium (mCDM11) was composed, namely mCDM7 + Ser, Gly, Glu, and Gln. This medium is quite supportive of growth of PA1002 as an $\mathrm{OD}_{600}$ of 2.4 was obtained in an overnight culture (table 3, entry B1), compared to an $\mathrm{OD}_{600}$ of 3.1 for mCDM20.

The one-at-a-time approach was used to explore if one or two amino acids present in mCDM20 but not in mCDM11 are responsible for this difference in $\mathrm{OD}_{600}$ (table 3). Only Asn and Tyr increased the $\mathrm{OD}_{600}$ from 2.4 to 2.7 and 2.6 , respectively (table 3 , entries B3 and B7). When Tyr and Asn were both added to mCDM11 (table 3, entry $\mathrm{B} 8$ ) an $\mathrm{OD}_{600}$ value similar to the $\mathrm{OD}_{600}$ for mCDM20 was obtained, thus showing that the amino acids Asp, Ala, Lys, Phe, Thr, Pro, and Cys, present in mCDM20, do not support additional growth. This medium is called mCDM13, a new CDM composed of 24 chemicals including 13 amino acids (table 1), in which the L. lactis Trp auxotroph PA1002 grows as well as it does in the 50-component CDMbasis.

The Production Level of Recombinant Protein in L. lactis PA1002 Grown in CDMbasis, mCDM20, or $m C D M 13$

The simplification of CDM aims to express Trp analog-labeled protein efficiently and cost-effectively. Two different proteins, LmrR and W20 lysM tandem, were used to investigate the impact of either CDMbasis, mCDM20, or mCDM13 on the production levels of these proteins. LmrR is a transcriptional regulator found in $L$. lactis and its gene was cloned in a pNSC8048 vector behind a $\mathrm{P}_{\text {nis }}$ promotor. The $\mathrm{W} 20$ lysM tandem protein consists of two engineered lysin motifs from the L. lactis enzyme $\mathrm{N}$-acetylglucosaminidase (AcmA). The gene of this single Trp-containing protein was cloned in a nisin-inducible expression-secretion vector derived from pNZ8048. The W20 lysM tandem protein is thus secreted into the medium. The production levels of these two proteins each labeled with either 5-fluoroTrp or 5-methylTrp in L. lactis PA1002 grown in CDMbasis, mCDM20, and $\mathrm{mCDM} 13$, respectively, were determined after o/ $\mathrm{n}$ induction with nisin. The $\mathrm{OD}_{600}$ values of the cultures are presented in figures 2 and 3 . Under all tested conditions, the growth was the lowest in MCDM13 and the presence of 5-methylTrp in the medium was more toxic for cell growth than 5-fluoroTrp. Expression levels of the proteins, per volume unit cell culture, were determined for all 6 alloproteins by lysing the cells with glass beads and loading the whole cell extracts on a SDS-PAGE gel. Protein band intensities were determined and the results are presented in table 4 . For W20 LysM tandem protein la- 


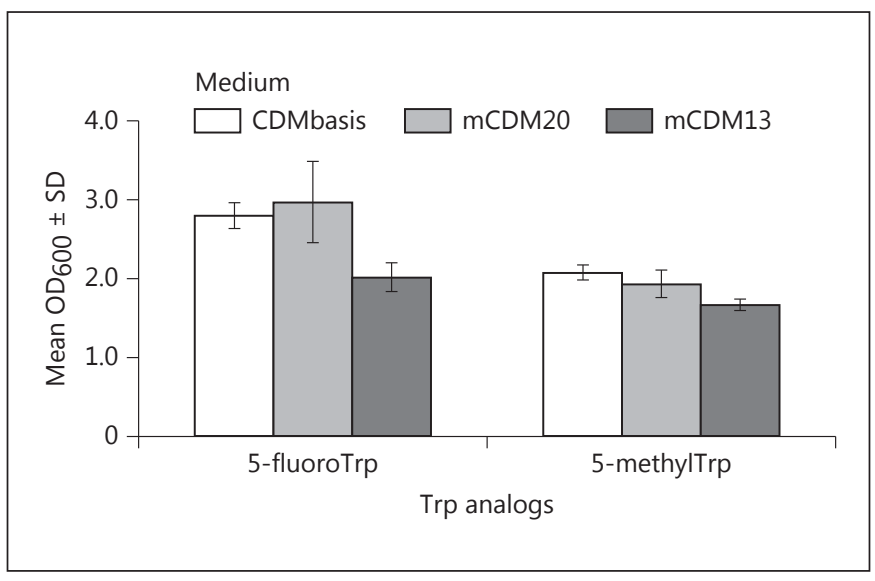

Fig. 2. $\mathrm{OD}_{600}$ after $\mathrm{o} / \mathrm{n}$ incubation of PA1002 cultures expressing LmrR protein in different synthetic media supplemented with a Trp analog.

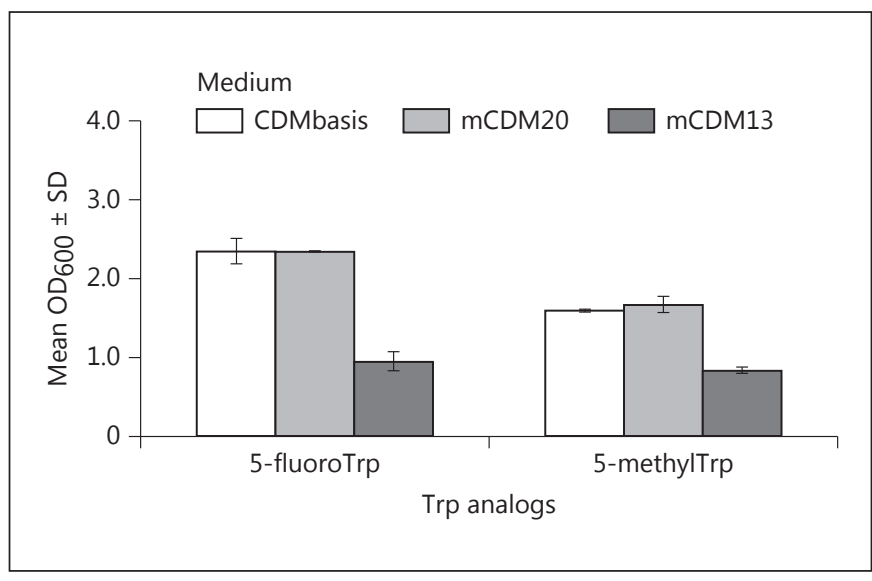

Fig. 3. $\mathrm{OD}_{600}$ after $\mathrm{o} / \mathrm{n}$ incubation of PA1002 cultures expressing W20 lysM protein in different synthetic media supplemented with a Trp analog.

Table 4. Expression levels and Trp analog incorporation efficiencies of W20 lysM proteins and LmrR proteins

\begin{tabular}{|c|c|c|c|c|c|c|c|}
\hline \multirow[t]{2}{*}{ Protein } & \multicolumn{4}{|c|}{ 5-fluoroTrp } & \multicolumn{3}{|l|}{ 5-methylTrp } \\
\hline & position & CDMbasis & $\mathrm{mCDM} 20$ & mCDM13 & CDMbasis & $\mathrm{mCDM} 20$ & $\mathrm{mCDM} 13$ \\
\hline \multicolumn{8}{|l|}{ W20 } \\
\hline Expression level, AU & & $3,000 \pm 500$ & $7,000 \pm 1,300$ & $3,900 \pm 1,200$ & $2,700 \pm 800$ & $4,100 \pm 70$ & $1,700 \pm 20$ \\
\hline$\%$ analog & 20 & $98 \%$ & $96 \%$ & $96 \%$ & $95 \%$ & $94 \%$ & $96 \%$ \\
\hline \multicolumn{8}{|l|}{ LmrR } \\
\hline Expression level, AU & & $5,300 \pm 400$ & $7,700 \pm 900$ & $7,100 \pm 400$ & $7,700 \pm 500$ & $18,000 \pm 200$ & $21,000 \pm 1,100$ \\
\hline \multirow[t]{3}{*}{$\%$ analog } & 67 & $\geq 99 \%$ & $98 \%$ & $97 \%$ & $\geq 99 \%$ & $96 \%$ & $\geq 99 \%$ \\
\hline & 96 & $\geq 99 \%$ & $\geq 99 \%$ & $\geq 99 \%$ & $\geq 99 \%$ & $\geq 99 \%$ & $96 \%$ \\
\hline & 120 & $\geq 99 \%$ & $\geq 99 \%$ & $\geq 99 \%$ & $\geq 99 \%$ & $\geq 99 \%$ & $\geq 99 \%$ \\
\hline
\end{tabular}

beled with 5-fluoroTrp, expression in $\mathrm{MCDM} 20$ and mCDM13 were up to 2.3 times higher compared to CDMbasis as the expression medium. Expression of 5-methylTrp-labeled W20 lysM tandem protein was also higher in $\mathrm{mCDM} 20$ than in CDMbasis, but lower in mCDM13 $(-35 \%)$. For LmrR, a different picture was observed as the expression level was 2.3-2.7 times higher for both the 5-fluoroTrp- and 5-methylTrp-labeled protein in mCDM13. Note that the $\mathrm{OD}_{600}$ was the lowest in this medium (fig. 2), indicating cells in this medium obtained a much higher expression level than in the other two media investigated. Taken together, the highest expression levels of the two test proteins were obtained in one of the two newly developed media.
The Incorporation Efficiency of Trp Analogs in

CDMbasis, $m C D M 20$, and $m C D M 13$

Besides a high expression level of alloprotein, also the labeling efficiency is of importance. The incorporation efficiency of Trp analogues into LmrR and W20 lysM tandem protein were determined by MALDI-TOF (table 4 ). In CDMbasis, W20 lysM protein could be labeled with 5-fluoroTrp or 5-methylTrp with an incorporation efficiency of 98 and 95\%, respectively, and similar incorporation efficiencies were obtained when mCDM20 or mCDM13 were used. LmrR contains 3 Trp positions at 67,96 , and 120, and labeling efficiencies at these 3 positions were determined when cells were cultured in CDMbasis, mCDM20, or mCDM13, supplemented by either 5-fluoroTrp or 5-methylTrp. In all LmrR samples, incor- 
poration efficiencies at the 3 positions were $96 \%$ or higher. In summary, a very high Trp analog incorporation efficiency can be obtained when PA1002 is cultured in the two newly developed media.

\section{Discussion}

In this report, new synthetic media have been developed specifically for the production of recombinant alloproteins by the L. lactis Trp auxotroph PA1002, a derivative of L. lactis strain MG1363 [El Khattabi et al., 2008]. Several chemically defined media for $L$. lactis have been developed over the years [Aller et al., 2014; Jensen and Hammer, 1993; Otto et al., 1983; Poolman and Konings, 1988; Zhang et al., 2009] for metabolic studies, and defined media also allow the expression of heterologous proteins labeled with unnatural amino acids [Berntsson et al., 2009; El Khattabi et al., 2008; Petrovic et al., 2012, 2013a, 2013b; Shao et al., 2015]. Most of these media support growth for prolonged incubation times, but a less demanding role of the CDM is required for the production of alloproteins by Trp auxotroph PA1002. Here the medium is only used to keep the cells viable during alloprotein expression for $16 \mathrm{~h}$, when cell growth is minimal or even absent because of the toxicity of the Trp analogs. Development of chemically defined media for L. lactis gave insight into the importance of most components [Zhang et al., 2009]. Steered by this information, two much simpler chemically defined media, mCDM20 and mCDM13, were developed. Both of the new media support high-density growth of PA1002 in the presence of Trp and without an inducer. When used as an expression medium in the PA1002-based protocol for the production of Trp analog-labeled alloproteins, protein yields per culture volume up to 2-3 times higher than the starting-off CDM were obtained, suggesting an adverse effect of one or more of the components not present in mCDM13 and mCDM20. In comparing the mCDM13 and mCDM20 media, the latter supported higher cell densities in all alloprotein expression experiments presented in figures 2 and 3; however, the amount of W20 alloprotein produced per cell was similar (5-methylTrp-labeled W20 lysM tandem) to much higher (5-fluoroTrp-labeled W20 lysM tandem) in mCDM13. For the nonsecreted LmrR, the expression yields were significantly higher in cells cultured in mCDM13 compared to mCDM20. This benefits the purification of the expressed protein, making the simpler mCDM13 the most attractive medium for alloprotein production. As preparation of the synthetic medium is the most labor intensive part of the PA1002-based alloprotein expression protocol, the new media make this system significantly less labor intensive and more cost-efficient. In conclusion, the simplest synthetic media known for L. lactis that are optimally suited for the efficient production of Trp analog-labeled alloproteins are presented in this report.

\section{Experimental Procedures}

\section{Bacterial Strain and Plasmids}

The L. lactis Trp auxotroph PA1002 [El Khattabi et al., 2008], which harbors the pMG36e-trprs plasmid for expressing lacTrpRS [Petrovic et al., 2013b], was used in this study. To test the system with two different alloproteins, plasmid pNZ8048-PA295 (containing the gene for the W20 LysM tandem protein [Petrovic et al., 2012]) or plasmid pNSC8048-lmrR (containing the gene for the multidrug transcriptional repressor protein LmrR [Agustiandari et al., 2008]) was electrotransformed into L. lactis PA1002 containing the pMG36e-trprs plasmid.

\section{Cultivation and Protein Expression}

The 50-component CDM was prepared essentially as described before [Berntsson et al., 2009]. For the preparation of mCDM media, a $1.18 \times$ basic buffer, $\mathrm{pH}=6.5-6.6$, was used consisting of $\mathrm{KH}_{2} \mathrm{PO}_{4}, \mathrm{~K}_{2} \mathrm{HPO}_{4}, \mathrm{MOPS}, \mathrm{MgSO}_{4}$, and potassium acetate. $845 \mathrm{ml}$ of filter sterilized basic buffer was mixed with $75 \mathrm{ml}$ of $20 \%$ glucose (autoclaved), $20 \mathrm{ml}$ of $50 \times$ vitamin mix (filter sterilized), and $50 \mathrm{ml}$ of $20 \times$ amino acid mix without Trp (filter sterilized). To this mixture, $10 \mathrm{ml}$ of $0.05 \% \mathrm{ZnSO}_{4}$ solution (filter sterilized) was added. Cells were cultured without shaking at $30^{\circ} \mathrm{C}$. For cultivation, $1 \mathrm{ml}$ overnight culture of L. lactis Trp auxotroph PA1002 in GM17 medium with $5 \mu \mathrm{g} / \mathrm{ml}$ of chloramphenicol and $75 \mu \mathrm{g} / \mathrm{ml}$ of erythromycin was used to inoculate $50 \mathrm{ml}$ of fresh GM17 with $5 \mu \mathrm{g} / \mathrm{ml}$ of chloramphenicol and $75 \mu \mathrm{g} / \mathrm{ml}$ of erythromycin, and incubated until an $\mathrm{OD}_{600}$ of 0.8 was reached. The cells were centrifuged at $5,500 \mathrm{~g}$ for $8 \mathrm{~min}$ and the pellet was resuspended in PBS. This procedure was repeated two more times. Subsequently, the cells were resuspended in $50 \mathrm{ml}$ of synthetic medium (table 1), excluding Trp, and this culture was left for $30 \mathrm{~min}$ at $30^{\circ} \mathrm{C}$. The expression of the recombinant proteins, W20 lysM tandem or LmrR, was induced by adding $8 \mathrm{ng} / \mathrm{ml}$ of nisin and $1 \mathrm{mM}$ of Trp or Trp analog, and the culture was left at $30^{\circ} \mathrm{C}$ for $16 \mathrm{~h}$ [Petrovic et al., 2013].

\section{SDS PAGE Gel Electrophoresis and Protein Expression Level} Determination

For W20 lysM tandem protein samples, the supernatant of the centrifuged cell culture was used because W20 lysM tandem is secreted by $L$. lactis into the medium. For LmrR, the cell pellet was resuspended into $20 \mathrm{mM}$ Tris- $\mathrm{HCl}$ buffer, $\mathrm{pH} 8.0$, with $50 \mathrm{mM}$ of $\mathrm{NaCl}$, followed by the addition of $10 \mathrm{mM}$ of $\mathrm{MgSO}_{4}, 100 \mu \mathrm{g} / \mathrm{ml}$ of DNase I, complete protease inhibitor (Roche), and glass beads (50-100 mesh). After opening the cells using a MINI-beadbeater (BioSpec Products) and centrifugation, the supernatant was mixed with loading buffer and loaded on a SDS-PAGE gel. Gels were stained with $0.05 \%$ Coomassie Brilliant Blue R-250. The protein band intensity was evaluated using the program ImageMaster (Pharmacia). 
Protein Purification and Mass Spectrometry

W20 lysM tandem was purified with a HiTrap Phenyl HP column (GE Healthcare) using a fast protein liquid chromatography system (Äkta FPLC, Uppsala, Sweden) as described elsewhere [Petrovic et al., 2012]. LmrR was purified using two columns, a StrepTactin Sepharose and a HiTrap heparin HP column as described previously [Agustiandari et al., 2008].

For mass spec analysis, the buffer of the two proteins was changed to $100 \mathrm{mM}$ of ammonium bicarbonate buffer using an Amicon concentrator (MWCO $10 \mathrm{kDa}$ ). $1 \mu \mathrm{l}$ of $100-\mu \mathrm{g} / \mathrm{ml}$ trypsin was added to $20 \mu \mathrm{l}$ of protein solution (around $0.1 \mathrm{mg} / \mathrm{ml}$ protein) and incubated for $2-3 \mathrm{~h}$ at $37^{\circ} \mathrm{C}$. A $1-\mu \mathrm{l}$ sample was spotted on a MALDI plate and mixed immediately with an equal volume of 10 $\mathrm{mg} / \mathrm{ml}$ a-cyano-4-hydroxycinnamate (LaserBio Labs) in $50 \%$ acetonitrile $/ 0.1 \%(\mathrm{v} / \mathrm{v})$ trifluoroacetic acid. Spots were measured using a Voyager DE-PRO MALDI-TOF (time of flight) instrument
(Applied Biosystems). The incorporation efficiency of the Trp analogue into proteins was calculated after measuring the peak areas of the peptide containing either Trp or Trp analogue.

\section{Acknowledgement}

This work was financially supported by the China Scholarship Council and FAPESP. We thank Dr. B.W. Dijkstra for critical reading of the manuscript.

\section{Disclosure Statement}

The authors declare that they have no conflict of interest.

\section{References}

Agustiandari H, Lubelski J, van Saparoea HB, Kuipers OP, Driessen AJ: LmrR is a transcriptional repressor of expression of the multidrug $\mathrm{ABC}$ transporter $1 \mathrm{mrCD}$ in Lactococcus lactis. J Bacteriol 2008;190:759-763.

Aller K, Adamberg K, Timarova V, Seiman A, Festsenko D, Vilu R: Nutritional requirements and media development for Lactococcus lactis IL1403. Appl Microbiol Biotechnol 2014;98:5871-5881.

Berntsson RP, Oktaviani, NA, Fusetti, F, Thunnissen AM, Poolman, B, Slotboom, DJ: Selenomethionine incorporation in proteins expressed in Lactococcus lactis. Protein Sci 2009; 18:1121-1127.

Broos J: Biosynthetic incorporation of tryptophan analogs in proteins. Methods Mol Biol 2014; 1076:359-370.

Budisa N: Prolegomena to future experimental efforts on genetic code engineering by expanding its amino acid repertoire. Angew Chem Int Ed Engl 2004;43:6426-6463.

Connor RE, Tirrell DA: Non-canonical amino acids in protein polymer design. Polymer Rev 2007;47:9-28.

El Khattabi M, van Roosmalen ML, Jager D, Metselaar H, Permentier H, Leenhouts K, Broos J: Lactococcus lactis as expression host for the biosynthetic incorporation of tryptophan analogues into recombinant proteins. Biochem J 2008;409:193-198.
Jensen PR, Hammer K: Minimal requirements for exponential growth of Lactococcus lactis. Appl Environ Microbiol 1993;59:4363-4366.

Kuipers OP, de Ruyter PGGA, Kleerebezem M, de Vos WM: Controlled overproduction of proteins by lactic acid bacteria. Trends Biotechnol 1997;15:135-140.

Kunji ER, Slotboom DJ, Poolman B: Lactococcus lactis as host for overproduction of functional membrane proteins. Biochim Biophys Acta 2003;1610:97-108.

Morello E, Bermúdez-Humáran LG, Llull D, Solée V, Miraglio N, Langella P, Poquet I: Lactococcus lactis, an efficient cell factory for recombinant protein production and secretion. J Mol Microbiol Biotechnol 2008;14:48-58.

Otto R, Tenbrink B, Veldkamp H, Konings WN The relation between growth-rate and electrochemical proton gradient of Streptococcus cremoris. FEMS Microbiol Lett 1983;16:6974.

Petrovic DM, Hesp BH, Broos J: Emitting state of 5-hydroxyindole, 5-hydroxytryptophan, and 5-hydroxytryptophan incorporated in proteins. J Phys Chem B 2013a;117:10792-10797.

Petrovic DM, Leenhouts K, van Roosmalen ML, Broos J: An expression system for the efficient incorporation of an expanded set of tryptophan analogues. Amino Acids 2013b;44: 1329-1336.
Petrovic DM, Leenhouts K, van Roosmalen ML, Kleinjan F, Broos J: Monitoring lysin motifligand interactions via tryptophan analog fluorescence spectroscopy. Anal Biochem 2012; 428:111-118.

Poolman B, Konings WN: Relation of growth of Streptococcus lactis and Streptococcus cremoris to amino-acid transport. J Bacteriol 1988; 170:700-707.

Ross JBA, Rusinova E, Luck LA, Rousslang KW: Spectral enhancement of proteins by in vivo incorporation of tryptophan analogues; in Lakowizc JR (ed): Topics in Fluorescence Spectroscopy: Protein Fluorescence. New York, Kluwer Academic/Plenum Publishers, 2000, vol 6, pp 17-42.

Ross JBA, Szabo AG, Hogue CW: Enhancement of protein spectra with tryptophan analogs: fluorescence spectroscopy of protein-protein and protein-nucleic acid interactions. Methods Enzymol 1997;278:151-190.

Shao J, Korendovych IV, Broos J: Biosynthetic incorporation of the azulene moiety in proteins with high efficiency. Amino Acids 2015;47: 213-216.

Twine SM, Szabo AG: Fluorescent amino acid analogs. Methods Enzymol 2003;360:104-127.

Zhang G, Mills DA, Block DE: Development of chemically defined media supporting highcell-density growth of lactococci, enterococci, and streptococci. Appl Environ Microbiol 2009;75:1080-1087. 